Article

\title{
An Analysis of the Energetics of Tropical and Extra-Tropical Regions for Warm ENSO Composite Episodes
}

\author{
Zayra Christine Sátyro ${ }^{1}$, José Veiga ${ }^{2}$ \\ ${ }^{1}$ National Institute for Amazonia Research, Manaus, AM, Brazil. \\ ${ }^{2}$ Amazon State University - Institute of Technology, Manaus, AM, Brazil.
}

Received in September 24, 2015 - Accepted in June 15, 2016

\begin{abstract}
This study focuses on the quantification and evaluation of the effects of ENSO (E1 Niño Southern Oscillation) warm phases, using a composite of five intense El Niño episodes between $1979-2011$ on the Energetic Lorenz Cycle for four distinct regions around the globe: $80^{\circ} \mathrm{S}-5^{\circ} \mathrm{N}$ (region 1), $50^{\circ} \mathrm{S}-5^{\circ} \mathrm{N}$ (region 2), $30^{\circ} \mathrm{S}-5^{\circ} \mathrm{N}$ (region 3 ), and $30^{\circ} \mathrm{S}-30^{\circ}$ $\mathrm{N}$ (region 4), using Data from NCEP reanalysis-II. Briefly, the results showed that zonal terms of potential energy and kinetic energy were intensified, except for region 1, where zonal kinetic energy weakened. Through the analysis of the period in which higher energy production is observed, a strong communication between the available zonal potential and the zonal kinetic energy reservoirs can be identified. This communication weakened the modes linked to eddies of potential energy and kinetic energy, as well as in the other two baroclinic conversions terms. Furthermore, the results indicate that for all the regions, the system itself works to regain its stable condition.
\end{abstract}

Keywords: atmospheric energetics, Lorenz Cycle, ENSO, El Niño.

\section{Uma Análise da Energética de Regiões Tropicais e Extra-Tropicais para um Composto de Episódios Quentes de ENOS}

\begin{abstract}
Resumo
Este estudo foca na quantificação e avaliação dos efeitos da fase quente de eventos ENOS (El Niño - Oscilação Sul), utilizando um composto de cinco intensos episódios de El Niño entre 1979 - 2011, no Ciclo Energético Lorenz por quatro regiões distintas ao redor do globo: $80^{\circ} \mathrm{S}-5^{\circ} \mathrm{N}$ (domínio 1), $50^{\circ} \mathrm{S}-5^{\circ} \mathrm{N}$ (domínio 2), $30^{\circ} \mathrm{S}-5^{\circ} \mathrm{N}$ (domínio 3 ), e $30^{\circ} \mathrm{S}-30^{\circ} \mathrm{N}$ (domínio 4), utilizando os Dados do NCEP - Reanálise 2. Resumidamente, os resultados mostraram que termos zonais de energia potencial e energia cinética foram intensificadas, com exceção da região 1, onde a energia cinética zonal enfraqueceu. Através da análise do período em que é observada maior produção de energia, observa-se uma forte comunicação entre os reservatórios de energia potencial disponível zonal e energia cinética zonal. Esta comunicação enfraqueceu o modo associado à perturbação de energia potencial e cinética, bem como nos outros dois termos conversões baroclínicas. Além disso, os resultados indicam que, para todas as regiões, o sistema funciona para recuperar o seu estado estável.
\end{abstract}

Palavras-chave: energética atmosférica, Ciclo de Lorenz, ENSO, El Niño.

\section{Introduction}

Atmospheric energetics analysis has had a long history since Lorenz (1955) formulated the concept of the available potential energy and its relationship with the atmospheric general circulation. Today, through energetics, there are many studies in order to investigate the impact in the general circulation caused by emission of aerosols by active volcanoes (Silva and Satyamurty, 2013), monsoons
(Krishnamurti et al., 1998; Gutierrez et al., 2009), ENOS events (Veiga et al., 2013), by increasing the concentration of greenhouse gases (Bohr, 1995; Deckers and von Storch 2010, 2011, 2012), among others.

Da Silva and Satyamurty, in 2013, studied the Lorenz energy cycle in the Intertropical Convergence Zone (ITCZ) in the South American sector of the Atlantic. They observed a strong annual cycle in all the components of energy with maximum occurring in the summer. The $\mathrm{KZ}$

Autor de correspondência: Zayra Christine Sátyro, zayra.pesquisa@gmail.com. 
(zonal kinetic energy) and AE (eddy potential energy) values have supported the claim that the intense warm ENSO of 1982 and/or the El Chichon eruption may have affected the circulation in the ITCZ region.

Deckers and von Storch (2010, 2011 and 2012) conduced studies about the dynamics of the atmospheric response relative to an increase in the $\mathrm{CO}_{2}$ concentration. They found a dual role of the heating pattern characterized by a strong heating in the tropical upper troposphere and in the lower levels of high latitudes, associated with the branch zonal available potential energy, an increase of the average potential energy in the upper troposphere and a decrease heating is mainly due to the static stability parameter.

Gutierrez et al. (2009), who studied the South American rainy season, observed after application of multivariate Empirical Orthogonal Function (EOF), that depending on which component of Lorenz Cycle was more pronounced at each phase of the South American Monsoon System could be used as an indicator of the onset of the rainy season.

Veiga et al. (2013), using the energy flow charts of a limited area, analyzed the energy cycle in a region overlooked by the Walker Circulation and its relationship with strong episodes of ENSO. They concluded that for a composite of El Niño events the tropical atmosphere is characterized by an increase in zonal potential energy, a decrease of eddy potential energy, and a reduction in kinetic energy fields. All three factors weakened the Walker circulation.

Differently from Veiga et al., 2013, who conducted the study for the tropical region that encompassed only the limits of the Walker circulation (latitude $5^{\circ} \mathrm{N}$ and $10^{\circ} \mathrm{S}$, longitude $120^{\circ} \mathrm{E}$ and $80^{\circ} \mathrm{W}$ ), in this paper, the study is conducted for regions located in tropical and extratropical regions. More, Veiga et al., 2013 focused their findings on the results obtained for two-dimensional analysis (pressure levels vs. time), while this work is based on the temporal variation of integrated energy components in the atmospheric volume. The main purpose behind the selected regions is to quantify and evaluate the impact of strong El Niño events on the energetics of remote (far from the EL Niño domain) areas.

In this context, the present study is aimed to use the energy equations related to the spatial area to assess the impact of El Niño events on Lorenz's Cycle in four different regions of the Earth. These events are ocean-atmosphere interaction phenomena associated with changes in climatological patterns of SST (Sea Surface Temperature), trade winds, surface pressure (Rasmusson and Carpenter, 1982; Kousky, 1984), and emission of longwave radiation by the ocean in the Equatorial Pacific region (Kane, 2008), thus changing the energy balance of the energy transformations that occur in the atmosphere-land-ocean system (Wallace and Hobbs, 2006). The El Niño episodes produce anomalous heat and water vapor fluxes into the tropical Pacific Ocean and the atmosphere. The associated anomalous convection causes upper-level divergence anomalies that per- turb the global circulation (Grimm and Tedeschi, 2009), leading to an increase in tropical temperature (Yeh et al., 2009), and therefore enhance the meridional temperature gradient and consequently yielding a gain in the production of potential energy. This may result in changes throughout the energy cycle including increases in zonal modes of generation of potential energy, potential energy, and kinetic energy as well as an intensification of the conversions related to zonal flow, as a reduction in the kinetic energy of the disturbance can be noted.

In sequence, the next section introduces the data and methodology applied. And after, the results and discussion are presented. Finally, we present the conclusions.

\section{Data and Methodology}

Data used in this study are from NCEP reanalysis2/NCAR and refer to a period of 33 years (1979-2011) taken from the NOAA-CIRES Climate Diagnostic Center, available at http://www.cpc.ncep.noaa.gov/. The reanalysis project began in the 1990s (Kalnay et al., 1996; Kistler et al., 2001) and continued the project of the National Meteorological Center/Climate Data Assimilation (NMC/CDAS), whose database originated from a wide global network of information gathering, including surface stations, radiosondes, and weather satellites, among others. The data correspond to daily averages with $2.5^{\circ} \times 2.5^{\circ}$ horizontal resolution, with 12 levels of isobaric surfaces (1000, $925,850,700,600,500,400,300,250,200,150$, and $100 \mathrm{hPa}$ ) for the variables of geopotential height, temperature, zonal and meridional components of the velocity wind vector, and omega, the vertical component of this vector in pressure coordinates.

Based on the reanalysis data, calculations of the atmospheric calculations were performed for the whole zonal domain (0 to 360 degrees), in four different zones located at $80^{\circ} \mathrm{S}-5^{\circ} \mathrm{N}$ (region 1 ), $50^{\circ} \mathrm{S}-5^{\circ} \mathrm{N}$ (region 2 ), $30^{\circ} \mathrm{S}-5^{\circ} \mathrm{N}$ (region 3), and $30^{\circ} \mathrm{S}-30^{\circ} \mathrm{N}$ (region 4) in order to study the change of energy cycles during the occurrence of El Niño events. The selection of five El Niño events was based on the ONI (Oceanic Niño Index). This index classifies an event as an El Niño episode when the arithmetic average of SST anomalies of three consecutive months in the El Niño 3.4 region is increased by $0.5^{\circ} \mathrm{C}$ and this increase is observed for five consecutive trimesters (e.g., ASO, SON, OND, NDJ, DJF). Based on the ONI index, the following events were selected: 1982-1983, 1986-1987, 1991-1992, 1997-1998, and 2009-2010. The composite in each domain was created according to the average of the atmospheric parameters of the events. Then, energy was calculated for the composite and for series of 33 years. The results were obtained from a comparison by percentage, between the composite of the energy cycle and its climatology and thus provided arguments for formulating a general picture of the atmospheric energy behavior for this type of 
event. The interval chosen to assess the impact of El Niño events was based on the period in which the SST in the El Niño 3.4 region remained above or equal to approximately $1{ }^{\circ} \mathrm{C}$, resulting in a gap between August of the first year (year 0) and April of the second year (year 0+1).

\subsection{Lorenz's equations}

As stated above, according to Lorenz's formulation, the available potential energy and the kinetic energy can be divided into basic state and eddies in relation to the basic state. The zonal modes are the amount of energy that would exist if there were not a component of disturbance. Such a disturbance is the excess energy with respect to zonal means (Lorenz, 1967). In the Lorenz Energy Cycle (LEC), the four boxes correspond to each of the energy reservoirs and the arrows represent the conventional directions of generation, conversion, or energy dissipation (Fig. 1). GZ and GE are the generation of zonal available potential energy and eddy available potential energy, respectively. The conversion terms are $\mathrm{CZ}$ (conversion from zonal available potential energy to zonal kinetic energy), CA (conversion from zonal available potential energy to eddy available potential energy), CE (conversion from eddy available potential energy to eddy kinetic energy), and CK (conversion from eddy kinetic energy to zonal kinetic energy). The terms DZ and DE are the dissipation of the zonal kinetic energy and the kinetic energy of the disturbances, respectively. Here these terms are presented on the LEC diagram, as they are important terms to close the balance on the equations presented below. However, as their values are achieved from a residual of the other terms the physical explanations about them and their relevance to the energy cycle are limited. Theory states that when dissipation terms are positive the kinetic energy from synoptic scale feeds small-scale processes (subgrid scale). The equations representing the conversion processes involved in the diagram (Eqs. (1) to (4)) are shown below:

$$
\begin{aligned}
& \frac{\partial \mathrm{AZ}}{\partial \mathrm{t}}=-\mathrm{CA}-\mathrm{CZ}+\mathrm{BAZ}+\mathrm{GZ} \\
& \frac{\partial \mathrm{AE}}{\partial \mathrm{t}}=\mathrm{CA}-\mathrm{CE}+\mathrm{BAE}+\mathrm{GE} \\
& \frac{\partial \mathrm{KZ}}{\partial \mathrm{t}}=\mathrm{CK}+\mathrm{CZ}+\mathrm{BKZ}-\mathrm{DZ} \\
& \frac{\partial \mathrm{KE}}{\partial \mathrm{t}}=\mathrm{CE}-\mathrm{CK}+\mathrm{BKE}-\mathrm{DE}
\end{aligned}
$$

$\mathrm{CZ}$ represents the conversion between zonal available potential energy and zonal kinetic energy through the upward movement of warm air and subsidence of cold air at different latitudes. This process indicates a negative correlation between zonal averages of $\omega$ and $T$ and hence a positive CZ. That is, zonal available potential energy (AZ) is converted into zonal kinetic energy (KZ) in the thermally

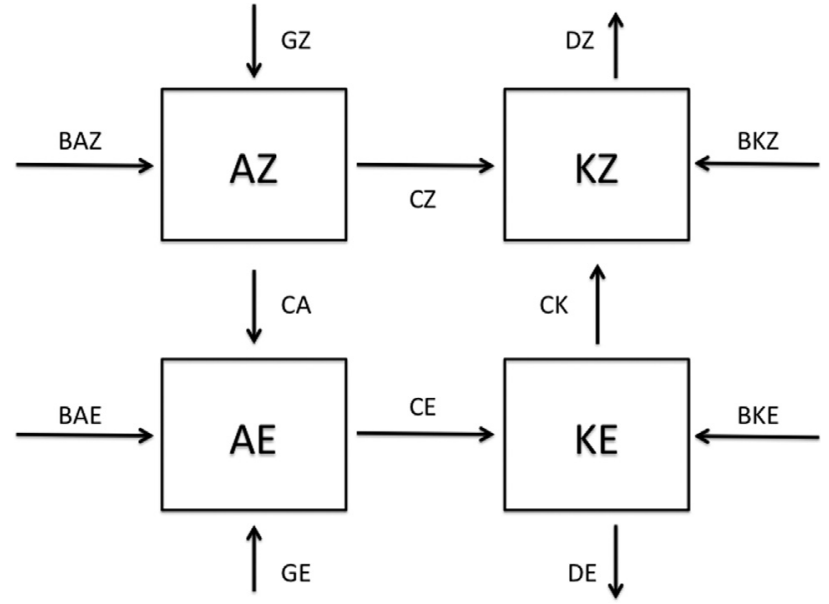

Figura 1 - Lorenz energy diagram representative of a 4 boxes.

direct Hadley cell (Li et al., 2007; Deckers and von Storch, 2011). CE (Eq. (19)) already represents the upward movement of warm air and subsidence of cold air in the vertical plane in the same circle of latitude (Marques et al., 2011). CA is written in terms of transport of sensible heat, both meridionally and vertically, associated with meridional and vertical gradients of temperature (Wiin-Nielsen et al., 1963). From a physical standpoint, in the lower troposphere, zonal average temperature decreases toward the poles. The wavelike disturbances transport warmer air to cooler latitudes and colder air to warmer latitudes, reducing the meridional thermal gradients, and consequently reducing AZ. As a result of this transport, along the same circle of latitude temperature, notable differences appear, thereby generating eddy available potential energy (AE) (Winston and Krueger, 1961). The term CK is written in terms of zonal momentum transport associated with perturbations along the meridional and vertical gradient of zonal wind and due to transports of momentum associated with perturbations along the meridional and vertical gradient of meridional wind (Marques et al., 2011).

There are others equations in the Appendix, which describe processes of transformation of energies and their relationship with the others cycle terms. The calculations of GZ, GE, DZ and DE were done as waste, as in the equations below:

$$
\begin{aligned}
& \mathrm{GZ}=\mathrm{CZ}+\mathrm{CA}-\mathrm{BAZ}+\frac{\partial \mathrm{AZ}}{\partial \mathrm{t}} \\
& \mathrm{GE}=\mathrm{CE}-\mathrm{CA}-\mathrm{BAE}+\frac{\partial \mathrm{AE}}{\partial \mathrm{t}} \\
& \mathrm{DZ}=-\frac{\partial \mathrm{KZ}}{\partial \mathrm{t}}+\mathrm{CZ}+\mathrm{CK}+\mathrm{BKZ} \\
& \mathrm{DE}=-\frac{\partial \mathrm{KE}}{\partial \mathrm{t}}-\mathrm{CK}+\mathrm{CE}+\mathrm{BKE}
\end{aligned}
$$




\section{Results and Discussion}

\subsection{Energy generation terms}

Figure $2 \mathrm{a}$ displays the temporal variation in zonal generation of available potential energy (GZ), which was weakened by approximately $2.72 \%$ in zone $2,4.83 \%$ in zone 3 , and $10.69 \%$ in zone 4 and in zone 1 it wasn't observed increase or decrease considerable. According to Winston and Krueger (1961) and Brown (1963), GZ is greatest when there is a high positive covariance between heating and temperature, that is, when the atmosphere is heated where the tem- perature is high and cooled where it is low. The reduction of GZ in zones 2, 3 and 4 should be related to a decrease of this covariance. GE is observed in Fig. 2b; it is strengthened in all zones by about $1.34 \%$ in zone $1,3.26 \%$ in zone $2,7.20 \%$ in zone 3 and $28.67 \%$ in zone 4 . When GE is intensified, it becomes less negative compared to its climatology. According to Brown (1963), the tendency of cold eddies to be warmed and warm eddies to be cooled decreased.

\subsection{Energy reservoir terms}

Figure $3 \mathrm{a}-\mathrm{d}$ presents a comparison between the temporal variations in terms of energy reservoirs with the com-
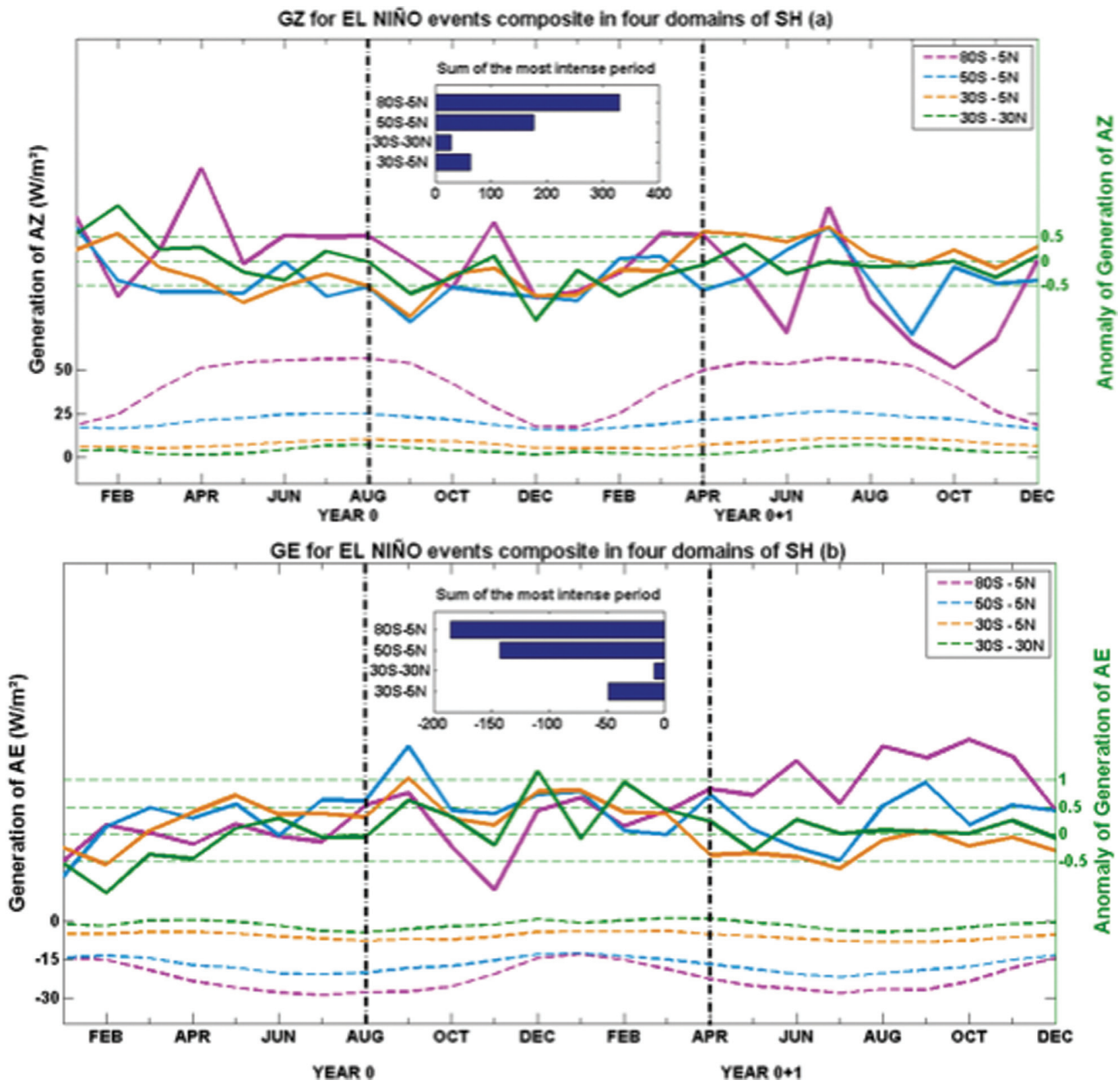

Figura 2 - Temporal variation of anomalies of GZ (a) and GE (b) for composites of El Niño events for four different regions: Domain $80^{\circ} \mathrm{S}-5^{\circ} \mathrm{N}$ (pink line), Domain $50^{\circ} \mathrm{S}-5^{\circ} \mathrm{N}$ (blue line), Domain $30^{\circ} \mathrm{S}-5^{\circ} \mathrm{N}$ (orange line) and Domain $30^{\circ} \mathrm{S}-30^{\circ} \mathrm{N}$ (green line). The bar graph in central shows the sum of all the energy produced between August and April for the term of generation (GE). At the bottom, dashed lines show the values of energy production for El Niño compounds in relation to each domain. Dashed lines of the domains are same colors of previous. Units are in $10^{5} \mathrm{~W} / \mathrm{m}^{2}$. 
posite of El Niños for the regions 1, 2, 3, and 4, whose curves of variation are related to the left hand axis. On the right hand axis, the anomalies of energy production in each domain are also shown. The sum of all energies produced between August and April and the sum of all the energies that crossed the boundary of the domain during this interval are displayed at the top of the graph. It is important to keep in mind that the graphs of the sums show only the total energy produced within the range, while the graphs of anomalies show, month by month, whether energy production was higher or lower compared to the climatology. So, the anomaly graphs do not specifically show in which period of the intervals there was higher energy production, but instead show in which period the anomalies were more intense.
Figure 3a shows the production of zonal available potential energy (AZ), which intensified in all areas: by about $1.65 \%$ (zone 1), $4.35 \%$ (zone 2), $8.60 \%$ (zone 3 ) and $8.65 \%$ (zone 4). Except for the last zone mentioned, the largest energy production was seen in the first half of the range (between August and December). In zones 1 and 4, anomalies were predominantly positive and more intense in the first half of the range. This allows us to suggest that tropical regions were more affected than those areas including, in addition to low latitudes, middle and high latitudes. This behavior may be connected to the pattern of decreasing temperature with latitude, which was the one suggested by Marques et al. (2010; 2011). Our results, therefore, suggest that El Niño episodes may be able to show a growth in the
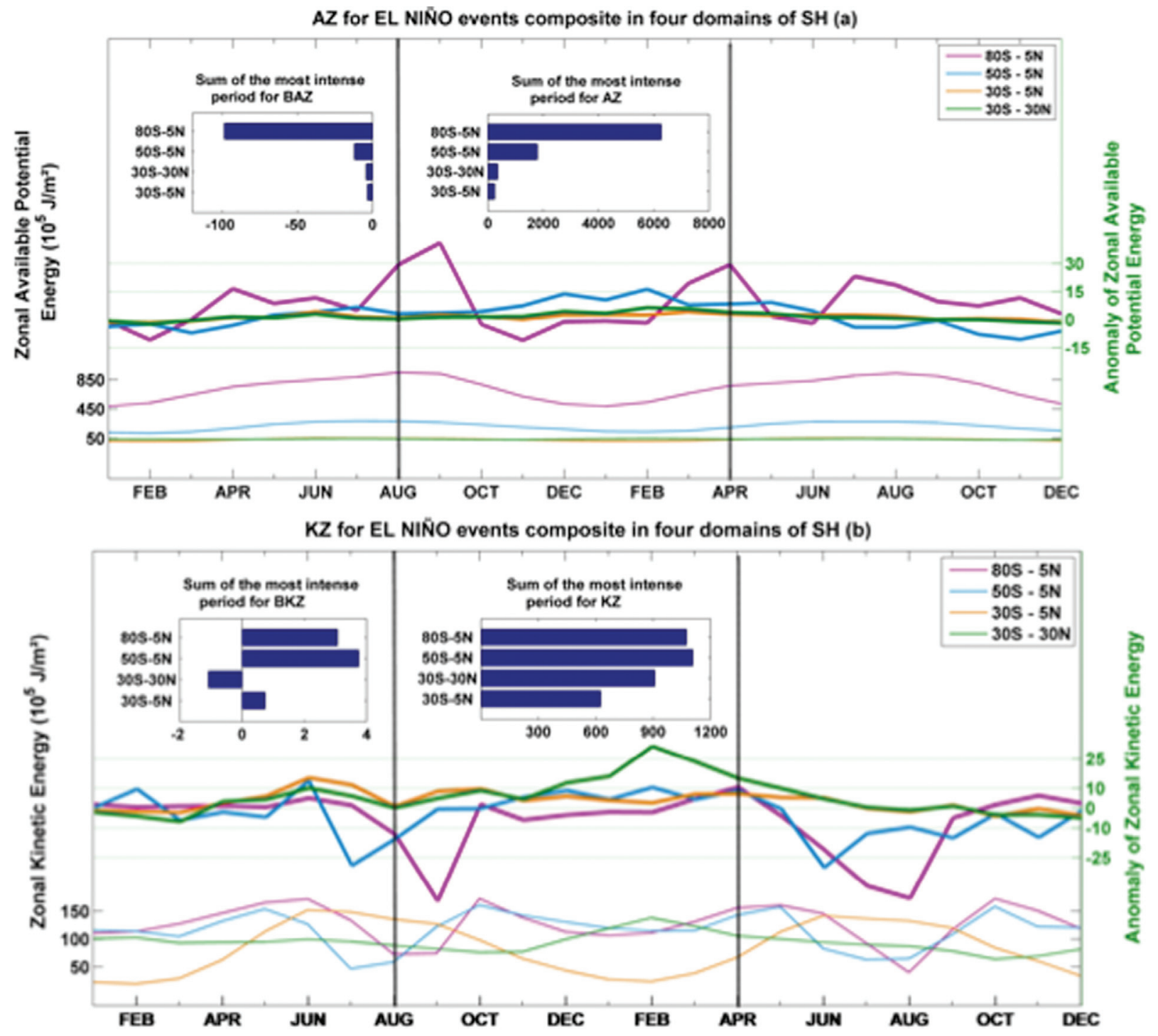

Figura 3 - Temporal variation of anomalies of AZ (a), KZ (b), AE (c) and KE (d) for composites of El Niño events for four different regions: Domain $80^{\circ}$ $\mathrm{S}-5^{\circ} \mathrm{N}$ (pink line), Domain $50^{\circ} \mathrm{S}-5^{\circ} \mathrm{N}$ (blue line), Domain $30^{\circ} \mathrm{S}-5^{\circ} \mathrm{N}$ (orange line) and Domain $30^{\circ} \mathrm{S}-30^{\circ} \mathrm{N}$ (green line). The bar graphs in central and on the left corner show the sum of all the energy produced between August and April for the term of reservoir (KE) and boundary (BKE), respectively. At the bottom, dashed lines show the values of energy production for El Niño compounds in relation to each domain. Dashed lines of the domains are same colors of previous. Units are in $10^{5} \mathrm{~J} / \mathrm{m}^{2}$. 

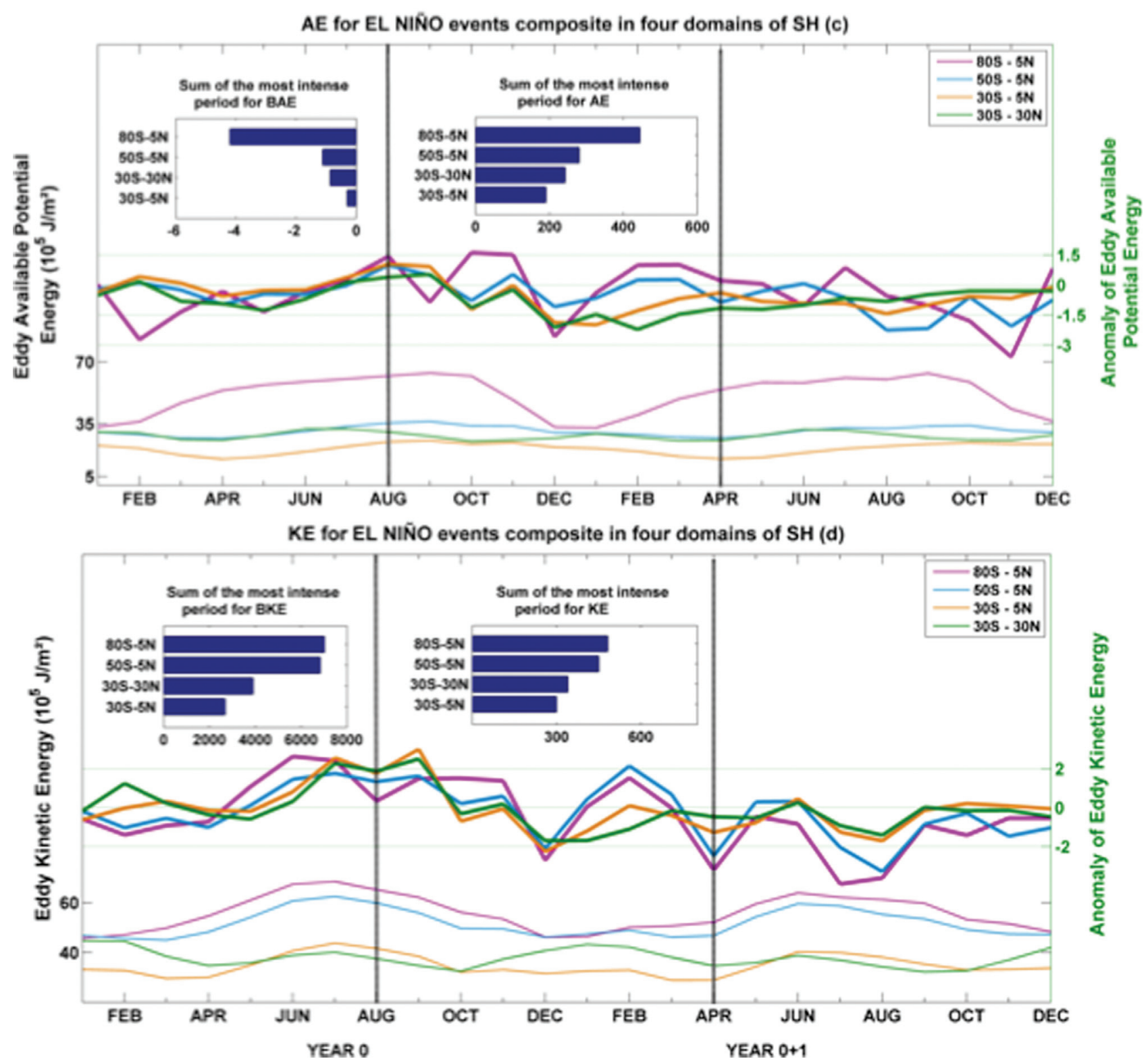

Figura 3 - cont.

display of AZ, which in turn is associated with an intensifying meridional temperature gradient. Also based on these results, the AZ energy rise observed in the tropical atmosphere is in agreement with the results found by Veiga et al. (2013).

Figure $3 \mathrm{~b}$ shows the production of zonal kinetic energy (KZ), which was intensified by about $2.39 \%$ (zone 2), $8.54 \%$ (zone 3), and $14.76 \%$ (zone 4 ) and decreased by about $5.03 \%$ (zone 1 ). In zones 3 and 4 , higher production of $\mathrm{KZ}$ was observed in the first period of the interval; the growth was about 2.3 and 1.4 times higher, respectively. In zones 1 and 2, higher production of KZ occurred in the second period of the interval. Anomalies were predominantly positive and more intense in the period of higher production. According to Kim and Kim (2013), the climatological
$\mathrm{KZ}$ production is related to the jet streams in the troposphere and the stratosphere, where there is a maximum production between $30^{\circ} \mathrm{N}$ and $30^{\circ} \mathrm{S}$. This suggests that the occurrence of El Niño strengthened the tropospheric and stratospheric jets, leading to a further intensification of the $\mathrm{AZ}$ production in the fields located in tropical latitudes (zones 3 and 4).

In Fig. 3c, displays the eddy available potential energy (AE), which showed weakness, except in zone 1. The greatest effect of the composite of El Niño occurred in zones 3 and 4 , which showed weakening by about $2.8 \%$ and $3.5 \%$, respectively. In other areas, the effect of El Niño was not even $1 \%$. In general a higher energy production was noted between August and December of year 0 (the first half of the interval) and coincides with the period of great- 
est production of AZ. All of this does not apply to domain 4, where energy production was relatively constant between August and April. The weakening of AE in zones 3 and 4 is consistent with the results of Veiga et al. (2013), who found that $\mathrm{AE}$ production in the tropical atmosphere decreases in the occurrence of El Niño. Furthermore, Li et al. (2007) suggested that the pattern of $\mathrm{AE}$ production is related to the continent-ocean thermal contrast. According to our results, it can be said that in the occurrence of events like El Niño, the thermal contrast is affected mostly in the region of tropical latitudes (zones 3 and 4) rather than in regions including middle and high latitudes (zones 1 and 2).

The production of eddy kinetic energy (KE) can be seen in Fig. 3d. KE experienced a tiny intensification in zones 1 and 2 and a lessening in zones 3 and 4 . This can be associated to the storm tracks over the Southern Ocean, according to Li et al., 2007, and also related to the slight intensification of tropospheric and stratospheric jet streams during El Niño (Fedorova and Carvalho, 2000), generating an increase in KE at mid-latitudes in the Southern Hemisphere. In the first case, the increased production of eddy kinetic energy takes place between August and December, a period in which there is a predominance of positive anomalies, contrary to what happens in the rest of the period. That is, the observed intensification in these areas is due to the anomaly of the first months' listing. Furthermore, zone 1 showed a reduction in zonal kinetic energy (KZ); this lower energy production happens in the first half of the range (which is marked by negative anomalies), while for all other terms of the reservoir, the largest production of energy takes place in the first half of the interval (marked by a predominance of positive anomalies). During the period between August and December, AZ contributed more to produce $\mathrm{AE}$ and this increase is reflected by an intensification of KE, which happens in the same period. However, from December the trend in $\mathrm{AZ}$ and $\mathrm{KE}$ is to present a decrease in production, evidenced by the weakening of the intensity of the anomalies. In this scenario, AZ decreases the transfer to $\mathrm{AE}$ and begins to contribute to the growth of $\mathrm{KZ}$ in the interval of recent months. As a general framework for zone 2, AE was weakened and $\mathrm{KZ}$ was strengthened, suggesting that AZ contributed more to produce an increase of KZ. This relationship becomes clearer when one notes that, between August and December, AZ had a higher energy production, which led to an increase in the production of $\mathrm{KZ}$, which is only seen from the first months of the second half of the range (evidenced by the predominance of positive anomalies). In the second half of the interval, AE production decreased. Despite the weakening of $\mathrm{AE}, \mathrm{KE}$ shows a notable strengthening, suggesting that the observed intensification in this area is perhaps associated with the magnitude of the boundary term, BKE.

Still in relation to the kinetic energy of the disturbances (Fig. 3d), in zones 3 and 4 there was a reduction in energy production between August and April. In those zones, $\mathrm{AZ}$ and $\mathrm{KZ}$ were strengthened while $\mathrm{AE}$ and $\mathrm{KE}$ were weakened. It was noted that in these domains the increases in production of $\mathrm{KZ}$ and $\mathrm{AZ}$ occur simultaneously. Probably due to this strong connection, most of AZ contributes to the production of $\mathrm{KZ}$, leading to a reduction in the production of $\mathrm{AE}$ and consequently a reduction of $\mathrm{KE}$.

\subsection{Energy conversion terms}

Figure 4a shows the behavior of conversion between the zonal energy forms AZ and $\mathrm{KZ}$ (CZ). CZ was strengthened in all areas: by about $12.98 \%$ (zone 1), $21.04 \%$ (zone 2), $14.13 \%$ (zone 3 ), and $3.85 \%$ (zone 4 ). This strengthening is probably associated with an intensification of the sensible heat transport due to increased vertical and meridional gradients of temperature. This condition indirectly leads to a $\mathrm{KE}$ deficit through the $\mathrm{CE}$ conversion, because more available zonal potential energy is used to produce zonal kinetic energy instead of eddy available potential energy, as happened in zones 3 and 4 . From the sum of all energy converted between August and April, it is seen that the highest production began in December, indicating that the increasing production of zonal kinetic energy in zones 1, 2, and 4 during the second half of the range has more to do with $\mathrm{CZ}$ than $\mathrm{CE}$ (although in the first domain the overall picture is weakening and the increase in production is only observed in the last months of the range).

In Fig. 4b, it can be seen that there is a conversion between the forms of potential energy available (CA). The overall picture shows that CA weakened in all areas: by approximately $1.33 \%$ (zone 1 ), $3.45 \%$ (zone 2 ), $6.73 \%$ (zone 3 ), and $20.3 \%$ (zone 4). The decrease in CA output is related to the reduction of the horizontal and vertical transport of heat through eddies. Such eddies decreased more in the tropics, probably due to the uniformity of temperature in this region, resulting in a greater decrease in zones 3 and 4. Analyzing each part of the range, it was observed that the lowest energy production happened in the second half (evidenced by the predominance of negative anomalies). This indicates that in zones 1,2 , and 4 , the strengthening of $\mathrm{CZ}$ and weakening of CA in the second half might be among the factors responsible for the increased production of $\mathrm{KZ}$ and $\mathrm{AE}$, respectively.

According to Fig. $4 \mathrm{c}$, it can be observed that $\mathrm{CK}$ intensified in all areas: by about $6.14 \%$ (zone 1), $3.78 \%$ (zone 2), $6.31 \%$ (zone 3 ), and $8.88 \%$ (zone 4), suggesting a strengthening of the climatological framework, that is, intensification equatorward of the positive contributions of tropospheric jets and stratospheric polar-night jets, as was suggested by Marques et al. (2010), and intensification of zonal motion as a result of the poleward transport of momentum by the motion of the eddies, as suggested by Kim and Kim (2013). Analyzing the studied domains, it was noticed that the largest production of CK occurred in the first half of the interval, except in zone 1 , where it was observed 
in December. This fact strengthens the idea that the increase in production observed in $\mathrm{KZ}$ was due to the energy transferred from the basic flow, as originally expected. In zone 2, there was also a lag between the periods of greatest energy production of $\mathrm{CK}$ and $\mathrm{KZ}$. This scenario allows us to infer that the increase in $\mathrm{KZ}$ came mainly from the energy basic flow, because a higher production of $\mathrm{KZ}$ occurred at the same time as the highest production of $\mathrm{CZ}$. In zone 3, the highest production of $\mathrm{CK}$ and $\mathrm{KZ}$ occurred at the same time, that is, in the first half of the interval, which indicated that the growth of $\mathrm{KZ}$ may depend more on $\mathrm{CK}$ than on $\mathrm{CZ}$, since the production of $\mathrm{KZ}$ decreased while production of $\mathrm{CZ}$ increased, which was observed in December. The difference in zone 4 is that $\mathrm{CK}$ was produced more in the second half of the interval, which coincides with increased production of $\mathrm{KZ}, \mathrm{CZ}$, and $\mathrm{AZ}$, indicating that the intensification of $\mathrm{KZ}$ is the result of both the energy transfer from the disturbances and from the basic flow.

The conversion between eddy modes (CE) for the studied domains is presented in Fig. 4d. It can be observed that the values of CE weakened by about $1.15 \%$ (zone 1), $1.83 \%$ (zone 3 ). For zones 2 and 4, it wasn't observed increased or decreased considerable. Furthermore, the decrease in CE production indicates that less energy is being converted into eddy kinetic energy during the occurrence of El Niño. This reduction is probably associated with the small temperature differences at the same latitude, because
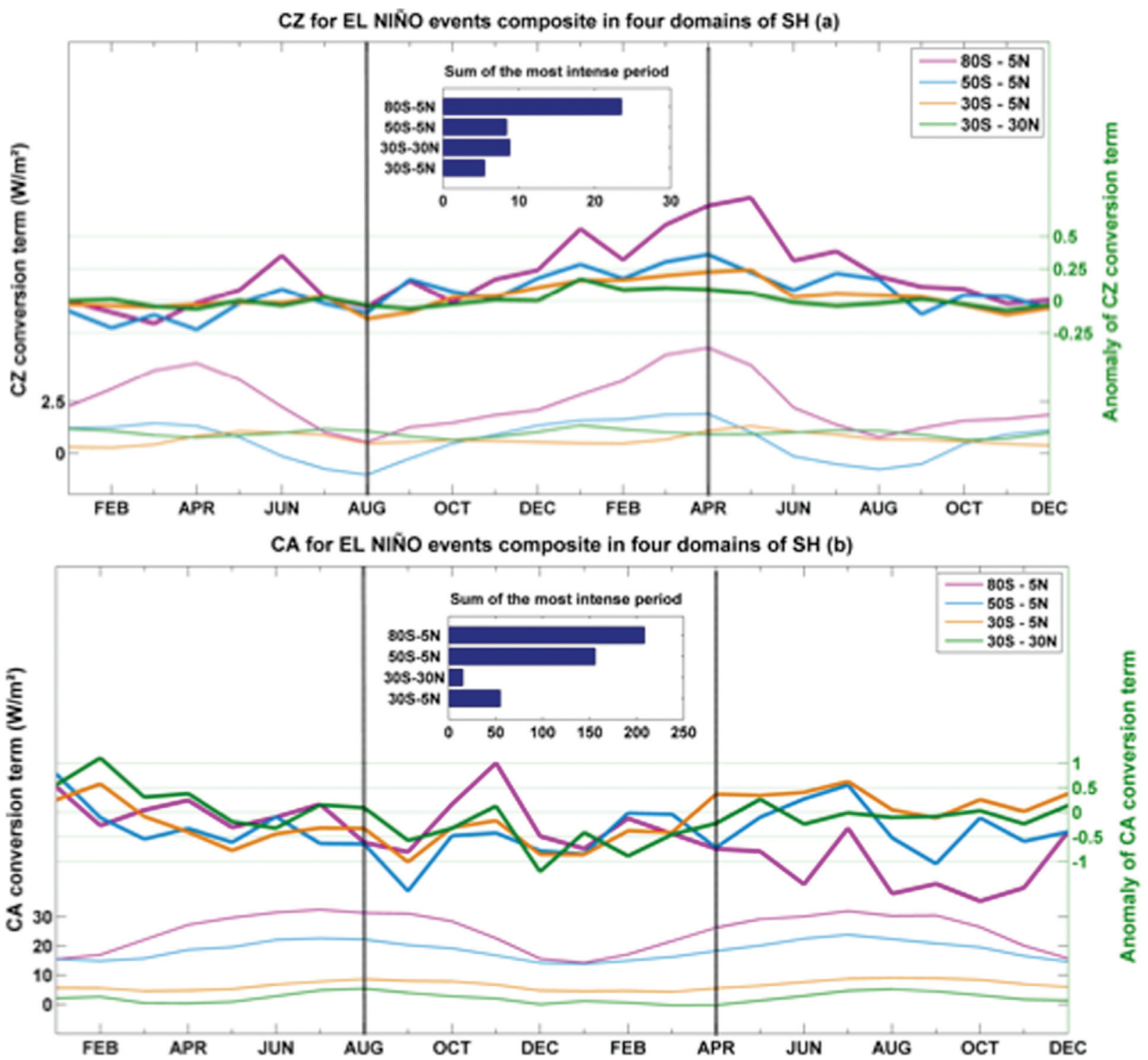

Figura 4 - Temporal variation anomalies of CZ (a), CA (b), CK (c) and CE (d) for composite of El Niño events for four different regions: Domain $80^{\circ}$ $\mathrm{S}-5^{\circ} \mathrm{N}$ (pink line), Domain $50^{\circ} \mathrm{S}-5^{\circ} \mathrm{N}$ (blue line), Domain $30^{\circ} \mathrm{S}-5^{\circ} \mathrm{N}$ (orange line) and Domain $30^{\circ} \mathrm{S}-30^{\circ} \mathrm{N}$ (green line). The bar graph in central shows the sum of all the energy produced between August and April for the term of conversion (CE). At the bottom, dashed lines show the values of energy production for El Niño compounds in relation to each domain. Dashed lines of the domains are same colors of previous. Units are in W/ $\mathrm{m}^{2}$. 

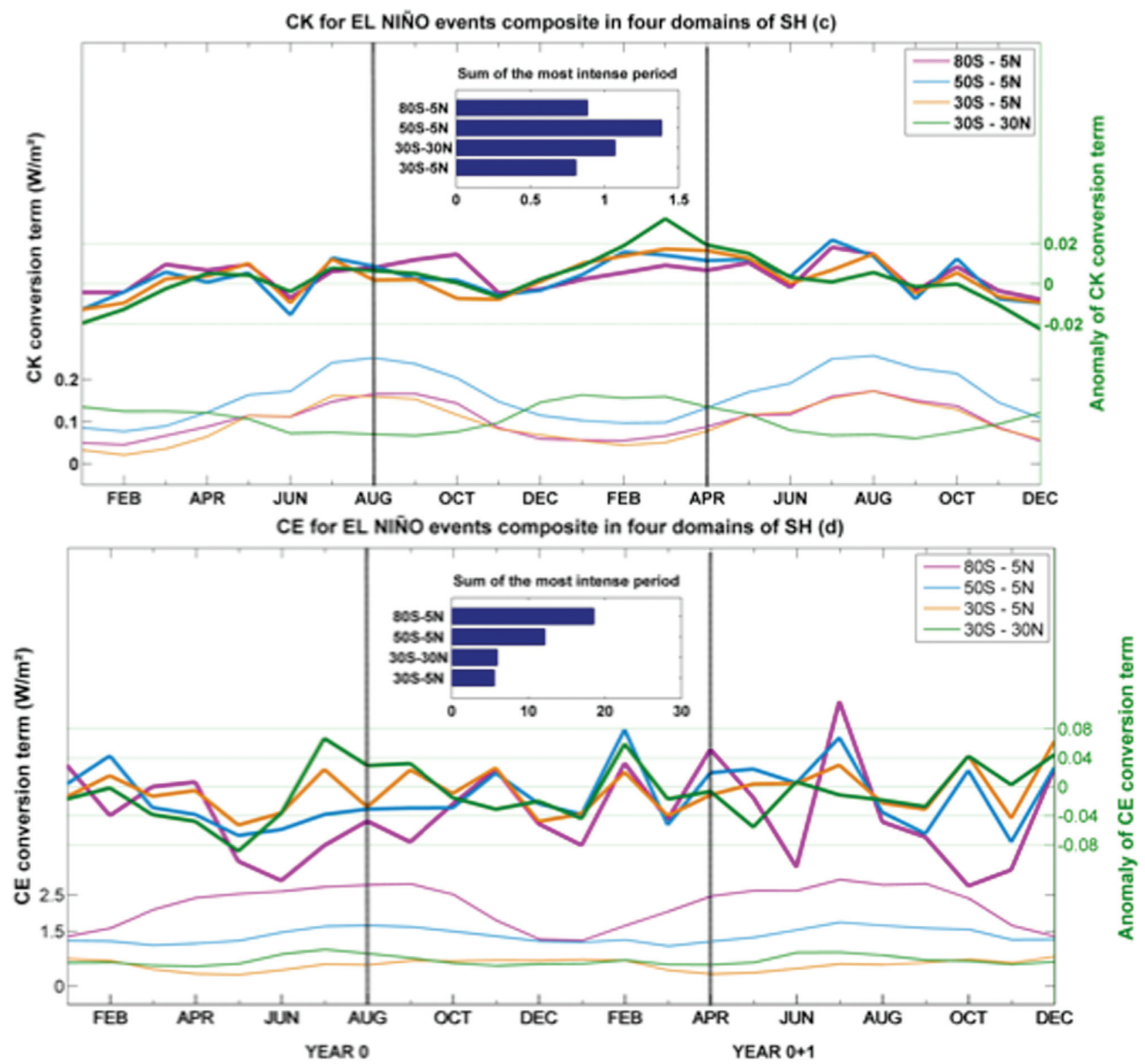

Figura 4 - (cont.)

CE is the result of warm air rising and cold air sinking, at the same circle of latitude, in the vertical plane. Considering each of the ranges, it is seen that the lowest energy production occurred in the second half of the range, matching the period of lowest energy production of $\mathrm{AE}$ and $\mathrm{KE}$.

\subsection{Volume integrated energy cycle}

The Lorenz energy cycle for the climatology and El Niño years, for the interval between August and April, is shown in Fig. 5. The convention of the conversion cycle is given by the direction of the arrows as in Fig. 1. As can be seen from the diagram, the barotropic branch $(\mathrm{AZ} \rightarrow \mathrm{CZ} \rightarrow$ $\mathrm{KZ}$ ) was strengthened, except zone 1 which showed weak- ening of KZ. The baroclinic branch, $\mathrm{CA} \rightarrow \mathrm{AE} \rightarrow \mathrm{CE} \rightarrow$ $\mathrm{KE}$, it was weakened, probably due to the strengthening of $\mathrm{CZ}$, indicating that most of $\mathrm{AZ}$ was destined to produce $\mathrm{KZ}$.

The boundary flux of AZ (BAZ) and AE (BAE) are negatives in all zones, working as a sink of zonal and eddy available energy. However, due to their low magnitudes relative to the other terms in the energy balance, their contributions to the energy reservoirs are less expressive. Climatologically, BKZ acts as a source of $\mathrm{KZ}$ for the zone 4 and as a sink for the zones 1,2 and 3. As can be seen BKZ keeps this feature during El Niño years. The boundary flux of $\mathrm{KE}$ (BKE) is positive, showing that this term contributes to the rising of $\mathrm{KE}$ in all zones. Its contribution is intensified for El Niño years. 


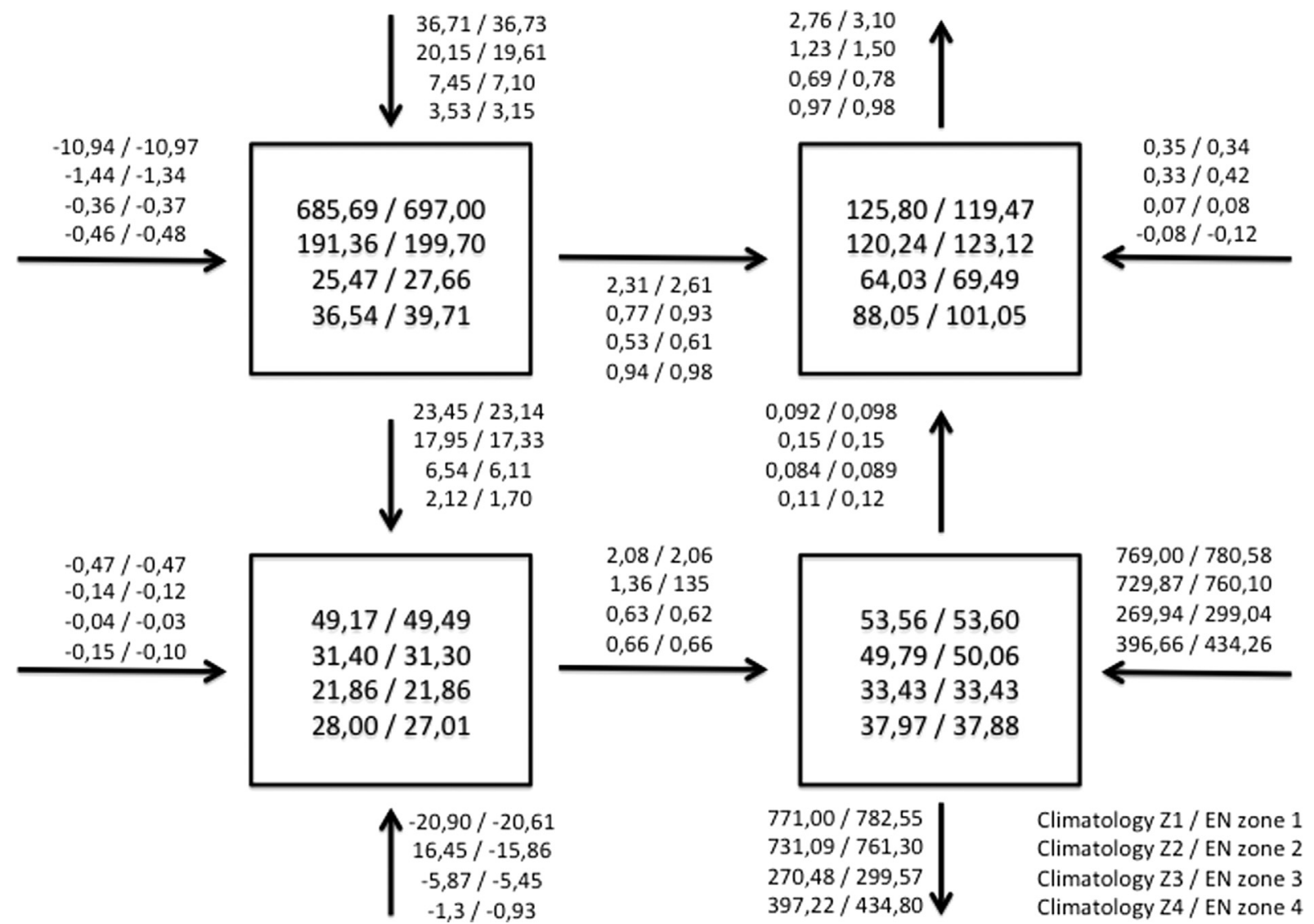

Figura 5 - Lorenz energy cycle for the climatology and El Niño composite. All values are representative of the interval between August and April. Units are $10^{5} \mathrm{~J} / \mathrm{W}^{2}$ for energy terms and $\mathrm{W} / \mathrm{m}^{2}$ for conversion and flux terms. All conventions follow the standard diagram outlined in Fig. 1.

\section{Conclusions}

In this paper, we present a broad energetic analysis relative to strong ENSO conditions for four specific domains around the globe. The main purpose of this study was to assess the impact of the warm phase of ENSO on the atmospheric energetics of four domains commonly affected by El Niño episodes. Here we use the space-time domain energetics technique to explore the main changes in the main branches of the Lorenz cycle and to highlight their impacts.

In general, for domains 3 and 4, during El Niño episodes, the results suggest that $\mathrm{AZ}$ and $\mathrm{KZ}$ as well as conversions of $\mathrm{CZ}$ and $\mathrm{CK}$ intensify. Furthermore, the values of $\mathrm{AE}$ and $\mathrm{KE}$ tend to weaken and as a result the conversion terms, CA and CE, decrease. Despite a weakness in CE, CK is strengthened in all domains and it is possible to suggest that the enhancement observed in $\mathrm{KZ}$ is connected to both $\mathrm{CZ}$ and $\mathrm{CK}$, despite the tendency toward weakening of KE. However, on analyzing the first and second halves of the interval to investigate when increased production of energy occurs, it was observed that the zones located in the tropics, zones 3 and 4, used a larger portion of CK to increase KZ. The other zones showed more dependence on energy supplies from the basic flow.
Furthermore, the results show that the occurrence of El Niño raises the temperature in the region of the tropics and thereby intensifies the meridional temperature gradient, which generates an increase in the production of potential energy available in the basic state. This increase in production does not remain indefinitely in the atmosphere because it becomes increasingly unstable, which in turn induces an intensification of eddies in zonal flow. In an attempt to return the atmosphere to equilibrium, the kinetic energy of the disturbances is transferred to basic flow. The weakening of $\mathrm{CA}$ and $\mathrm{CE}$ is a response in the dynamics of the atmosphere when the system itself works to regain the condition of stability.

The ENSO events are an ocean -atmosphere interaction phenomenon associated with change of climatological patterns of SST (sea surface temperature), subsurface water temperatures, trade winds and long wave radiation emission by the ocean in the Equatorial Pacific region. The occurrence of El Niño raises temperature in the Tropics and thus intensifies meridional gradient of temperature, generating a gain in potential energy production available from the basic state. This increase in production, does not remain indefinitely in the atmosphere because it becomes unstable. This in turn induces an enhancement in disturbances, and in the attempting of the environment return to equilibrium , 
the eddy kinetic energy is transfer to the basic flow. The increase of meridional gradient of temperature also intensifies the Hadley Circulation which is the main mechanism of energy transfer from the basic state to zonal flow. During La Niña events there is a reduction in thermal meridional gradient that decrease potential energy available. Thus, it is expected that El Niño increases zonal modes of generation of available potential energy, available potential energy and kinetic energy, as well as an increase in conversion terms releted to them. Consequently, a reduction in eddy kinetic energy (and conversion terms related to it) in favor of atmospheric stability . And the occurrence of La Nina expected adverse effects on the energy cycle.

That was observed when comparing these results to others about La Niña events. The main results involve the conversion branch $\mathrm{AZ}, \mathrm{CZ}, \mathrm{KZ}$ and $\mathrm{CK}$. Where $\mathrm{KZ}$ showed strength during of El Niño and weakening during La Niña, in all areas, except in zone 1 (which increased during La Niña and decreases during El Niño - opposite result to that expected). As it know, this term (KZ) is fueled both by the energy of the disturbances as by the potential energy of the basic state. The conversion that supplies the basic flow from the available potential energy (CZ), such as that supplies from eddies (CK) also increased during El Niño and decrease during La Nina, in all domains. Indicating that the supply KZ is strongly influenced by these two reservoirs: $\mathrm{AZ}$ and $\mathrm{KE}$.

In theory, the baroclinic branch $\mathrm{CA}, \mathrm{AE}, \mathrm{CE}$ also would have an opposite behavior to the different phases of ENSO. That is, in events like El Niño (La Niña) there would be a reduction (increase) in CA for the benefit of the increase (decrease) in CZ in turn would result in a decrease (increase) in $\mathrm{AE}$ and $\mathrm{CE}$. However, this behavior was only observed in the field 3 for the study of El Niño events.

\section{Acknowledgments}

We thank CAPES for financial support.

\section{References}

BOER, G.J. Some dynamical consequences of Greenhouse gas warming. Atmosphere-Ocean, v. 33, p. 731-751, 1995.

BROWN, J.A. A diagnostic of tropospheric diabatic heating and the generation of available potential energy. Tellus, v. 16, p. 371-388, 1964.

DECKERS, D.H.; VON STORCH, J.C. Energetics response to increases in Greenhouse gas concentration. Journal of Climate, v. 23, p. 3840-3887, 2010.

DECKERS, D.H.; VON STORCH, J.C. The energetics response to a warmer climate: relative contributions from the transient and stationary eddies. Earth System Dynamics, v. 2, p. 105-120, 2011.

DECKERS, D.H.; VON STORCH, J.C. Impact of warming pattern on global energetics. Journal of Climate, v. 33, p. 5223-5240, 2012.
FEDOROVA, N.; CARVALHO, M.H. Synoptic processes in La Niña and El Niño years. Part II: Frontal Zones. Brazilian Magazine of Meteorology, v. 15, n. 2, p. 57-72, 2000.

GRIMM, A.M.; TEDESCHI, R.G. ENSO and extreme rainfall events in South America. Journal of Climate, v. 22, p. 1589-1609, 2009.

GUTIERREZ, E.R.; DIAS, P.L.S.; VEIGA, J.A.; CAMAYO, R.; SANTOS, A. Multivariate analysis of the energy cycle of the South American rainy season. International Journal of Climatology, 2009.

KALNAY, E.; KANAMITSU, M.; KISTLER, R.; COLLINS, W.; DEAVEN, D.; GANDIN, L.; IREDELL, M.; SAHA, S.; WHITE, G.; WOOLLEN, J.; ZHU, Y.; CHELLIAH, M.; EBISUZAKI, W.; HIGGINS, W.; JANOWIAK, J.; MO, K. C.; ROPELEWSKI, C.; WANG, J.; LEETMAA, A.; REYNOLDS, R.; JENNE, R.; JOSEPH, D. The NCEP/NCAR 40-year reanalysis project. Bulletin of the American Meteorological Society, v. 77, p. 437-471, 1996.

KANE, R.P. Spatial and temporal characteristics of Outgoing Longwave Radiation (OLR): an update. Brazilian Magazine of Geophysics, v. 26, n. 2, 2008.

KIM, Y.H.; KIM, M.K. Examination of the global Lorenz energy cycle using MERRA and NCEP-reanalysis 2. Climate Dynamics, v. 40, p.1499-1513, 2013.

KISTLER, R.; KALNAY, E.; COLLINS, W.; S.SAHA; WHITE, G.; WOOLLEN, J.; CHELLIAH, M.; EBISUZAKI, W.; KANAMITSU, M.; KOUSKY, V.; DOOL, H.V.; JENNE, R.; FIORINO, M. The CEP/NCAR 50-year reanalysis: monthly means cd-rom and documentation. Bulletin of the American Meteorological Society, v. 82, p. 247-267, 2001.

KOUSKY, V.E.; KAGANO, M.T.; CAVALCANTI, I.F.A. A review of the Southern Oscillation: oceanic-atmospheric circulation changes and related rainfall anomalies. Tellus, p. 490-504, 1984.

KRISHNAMURTI, T.N.; SHINA, M.C.; JHA, B.; MOHANTY, U.C. A study of South Asian Monsoon energetics. Journal of the Atmospheric Sciences, v. 55, p. 2530-2548, 1998.

LI, L.; INGERSOLL, A.P.; JIANG, X.; FELDMAN, D.; YUNG, Y.L. LORENZ energy cycle of the global atmosphere based on reanalysis datasets. Geophysical Research Letters, v. 34, 2007.

LORENZ, E.N. Available potential energy and the maintenance of the general circulation. Tellus, 1955.

LORENZ, E.N. The nature and theory of the general circulation of the atmosphere World Meteorological Organization, v. 218, n. $161,1967$.

MARQUES, C.A.F.; ROCHA, A.; CORTE-REAL, J. Comparative energetics of ERA-40, JRA-25 and NCEP-R2 reanalysis, in the wave number domain. Dynamics of Atmospheres and Oceans, v. 50, p. 375-399, 2010.

MARQUES, C.A.F.; ROCHA, A.; CORTE-REAL, J. Global diagnostic of five state-of-the-art climate models. Climate Dynamics, v. 36, n. 10, p. 1767-1794, 2011.

RASMUSSON, E.M.; CARPENTER, T.H. Variations in tropical sea surface temperature and surface wind fields associated with the Southern Oscillation/El Niño. Monthly Weather Review, v. 110, p. 354-384, 1982.

SILVA, L.A.; SATYAMURTY, P. Evolution of the Lorenz energy cycle in the Intertropical Convergence Zone in the South American sector of the Atlantic Ocean. Journal of Climate, v. 26, p.3466-3481, 2013. 
VEIGA, J.A.P.; PEZZA, A.B.; AMBRIZZI, T.; RAO, V.B.; FRANCHITO, S.H.; YOSHIDA, M.C. The energy associated to the Pacific Walker Circulation and its relationship to ENSO. Atmospheric and Climate Sciences, v. 3, p. 627642, 2013.

WALLACE, J.M.; HOBBS, P.V. Atmospheric Science - An Introductory Survey. Academic Press: New York, 2006.

WIIN-NIELSEN, A.; BROWN, J.A.; DRAKE, M. On atmospheric energy conversions between the zonal flow and the eddies. Tellus, v. 15, p. 261-279, 1963.

WINSTON, J.S.; KRUEGER, A.F. Some aspects of a cycle of available potential energy. Monthly Weather Review, v. 89 , n. 9 , p. $307-318,1961$

YEH, S.W.; KUG, J.S.; DEWITTE, B.; KWON, M.H.; KIRTMAN, B.P.; JIN, F.F. El Niño in a changing climate. Nature, v. 461, p. 511-514, 2009.

\section{Internet Resources}

SST's Data source, http://www.cpc.ncep.noaa.gov/products/analysis_monitoring/ensostuff/ensoyears.shtml.

\section{Appendix}

Zonal mean of variable $\mathrm{X}$ between longitudes $\lambda_{1}$ and $\lambda_{2}$ is given by:

$[\mathrm{X}]_{\lambda}=\frac{1}{\lambda_{2}-\lambda_{1}} \int_{\mathrm{p}_{1}}^{\mathrm{p}_{2}} \mathrm{X} \mathrm{d} \lambda$

The zonal deviation field is given by:

$(\mathrm{X})_{\lambda}=\mathrm{X}-[\mathrm{X}]_{\lambda}$

Mean of $X$ in an area surrounded by longitudes $\lambda_{1}$ and $\lambda_{2}$ and latitudes $\phi_{1}$ e $\phi_{2}$ is given by:

$[\mathrm{X}]_{\lambda \phi}=\frac{1}{\lambda_{2}-\lambda_{1}} \frac{1}{\sin \phi_{2}-\sin \phi_{1}} \int_{\phi_{1}}^{\phi_{2} p_{p_{1}}^{p_{2}}} \mathrm{X} \cos \phi \mathrm{d} \lambda \mathrm{d} \phi(11)$

The deviation from the average in the area is given by:

$\left([\mathrm{X}]_{\lambda}\right)_{\phi}=[\mathrm{X}]_{\lambda}-[\mathrm{X}]_{\lambda \phi}$

The four terms of energy reservoirs are given by:

$$
\begin{aligned}
& \mathrm{BAZ}=\mathrm{c}_{1} \int_{\mathrm{p}_{1}}^{\mathrm{p}_{2} \int_{\lambda_{1}}^{\lambda_{2}}} \frac{1}{2[\sigma]_{\lambda \phi}}\left(2\left([\mathrm{~T}]_{\lambda}\right)_{\phi}(\mathrm{T})_{\lambda} \mathrm{u}+\left([\mathrm{T}]_{\lambda}\right)_{\phi}^{2} \mathrm{u}\right) \mathrm{d} \phi \mathrm{dp} \\
& +\mathrm{c}_{2} \int_{\mathrm{p}_{1}}^{\mathrm{p}_{2}} \frac{1}{2[\sigma]_{\lambda \phi}}\left(2\left[(\mathrm{v})_{\lambda}(\mathrm{T})_{\lambda}\right]_{\lambda}\left([\mathrm{T}]_{\lambda}\right)_{\phi} \cos \phi+\left([\mathrm{T}]_{\lambda}\right)_{\phi}^{2}[\mathrm{v}]_{\lambda} \cos \phi\right) \mathrm{dp} \\
& -\frac{1}{2[\sigma]_{\lambda \phi}}\left(\left[2(\omega)_{\lambda}(\mathrm{T})_{\lambda}\right]_{\lambda}\left([\mathrm{T}]_{\lambda}\right)_{\phi}+\left[[\omega]_{\lambda}\left([\mathrm{T}]_{\lambda}\right)_{\phi}^{2}\right]_{\lambda \phi}\right)
\end{aligned}
$$

$$
\begin{aligned}
& \mathrm{AZ}=\int_{\mathrm{p}_{1}}^{\mathrm{p}_{2}} \frac{\left[\left([\mathrm{T}]_{\lambda}\right)_{\phi}^{2}\right]_{\lambda \phi}}{2[\sigma]_{\lambda \phi}} \mathrm{dp} \\
& \mathrm{AE}=\int_{\mathrm{p}_{1}}^{\mathrm{p}_{2}} \frac{\left[(\mathrm{T})_{\lambda}^{2}\right]_{\lambda \phi}}{2[\sigma]_{\lambda \phi}} \mathrm{dp} \\
& \mathrm{KZ}=\int_{\mathrm{p}_{1}}^{\mathrm{p}_{2}} \frac{\left[[\mathrm{u}]_{\lambda}^{2}+[\mathrm{v}]_{\lambda}^{2}\right]_{\lambda \phi}}{2 \mathrm{~g}} \mathrm{dp} \\
& \mathrm{KE}=\int_{\mathrm{p}_{1}}^{\mathrm{p}_{2}} \frac{\left[(\mathrm{u})_{\lambda}^{2}+(\mathrm{v})_{\lambda}^{2}\right]_{\lambda \phi}}{2 \mathrm{~g}} \mathrm{dp}
\end{aligned}
$$

The four conversion terms are given by:

$$
\begin{aligned}
& \mathrm{CZ}=\int_{\mathrm{p}_{1}}^{\mathrm{p}_{2}}-\left[\left([\omega]_{\lambda}\right)_{\phi}\left([\mathrm{T}]_{\lambda}\right)_{\phi}\right]_{\lambda \phi} \frac{\mathrm{R}}{\mathrm{gp}} \mathrm{dp} \\
& \mathrm{CA}=\int_{\mathrm{p}_{1}}^{\mathrm{p}_{2}}\left[\frac{(\mathrm{v})_{\lambda}(\mathrm{T})_{\lambda}}{2[\sigma]_{\lambda \phi} \mathrm{r}} \frac{\partial\left([\mathrm{T}]_{\lambda}\right)}{\partial \phi}\right]_{\lambda \phi} \mathrm{dp} \\
& +\left[\frac{(\omega)_{\lambda}(\mathrm{T})_{\lambda}}{\mathrm{p}^{\mathrm{R} / \mathrm{c}_{\mathrm{p}}}} \frac{\partial\left([\mathrm{T}]_{\lambda}\right)_{\phi} \mathrm{p}^{\mathrm{R} / \mathrm{c}_{\mathrm{p}}}}{\partial \mathrm{p}[\sigma]_{\lambda \phi}}\right]_{\lambda \phi} \mathrm{dp} \\
& \mathrm{CE}=\int_{\mathrm{p}_{1}}^{\mathrm{p}_{2}}-\left[(\omega)_{\lambda}(\mathrm{T})_{\lambda}\right]_{\lambda \phi} \frac{\mathrm{R}}{\mathrm{gp}} \mathrm{dp}
\end{aligned}
$$

$$
\begin{aligned}
& \mathrm{CK}=\int_{\mathrm{p}_{1}}^{\mathrm{p}_{2}} \frac{1}{\mathrm{~g}}\left[(\mathrm{v})_{\lambda}(\mathrm{u})_{\lambda} \frac{\cos \phi}{\mathrm{r}} \frac{\partial[\mathrm{u}]_{\lambda}}{\partial \phi \cos \phi}\right]_{\lambda \phi} \mathrm{dp} \\
& +\int_{\mathrm{p}_{1}}^{\mathrm{p}_{2}} \frac{1}{\mathrm{~g}}\left[\frac{(\mathrm{v})_{\lambda}^{2}}{\mathrm{r}} \frac{\partial[\mathrm{v}]_{\lambda}}{\partial \phi}\right]_{\lambda \phi} \mathrm{dp} \\
& +\int_{\mathrm{p}_{1}}^{\mathrm{p}_{2}} \frac{1}{\mathrm{~g}}\left[[\mathrm{v}]_{\lambda}(\mathrm{u})_{\lambda}^{2} \frac{\tan \phi}{\mathrm{r}}\right]_{\lambda \phi} \mathrm{dp} \\
& +\int_{\mathrm{p}_{1}}^{\mathrm{p}_{2}} \frac{1}{\mathrm{~g}}\left[(\omega)_{\lambda}(\mathrm{u})_{\lambda} \frac{\partial[\mathrm{u}]_{\lambda}}{\partial \mathrm{p}}\right]_{\lambda \phi} \mathrm{dp} \\
& +\int_{\mathrm{p}_{1}}^{\mathrm{p}_{2}} \frac{1}{\mathrm{~g}}\left[(\omega)_{\lambda}(\mathrm{v})_{\lambda} \frac{\partial[\mathrm{v}]_{\lambda}}{\partial \mathrm{p}}\right]_{\lambda \phi} \mathrm{dp}
\end{aligned}
$$

The energy transport integrals are: 


$$
\begin{aligned}
& \mathrm{BAE}=\mathrm{c}_{1} \int_{\mathrm{p}_{1}}^{\mathrm{p}_{2}} \int_{\phi_{1}}^{\phi_{2}} \frac{1}{2[\sigma]_{\lambda \phi}}\left[\mathrm{u}(\mathrm{T})_{\lambda}^{2}\right] \mathrm{d} \phi \mathrm{dp} \\
& +\mathrm{c}_{2} \int_{\mathrm{p}_{1}}^{\mathrm{p}_{2}} \frac{1}{2[\sigma]_{\lambda \phi}}\left(\left[(\mathrm{T})_{\lambda}^{2}\right]_{\lambda} \cos \phi\right) \mathrm{dp} \\
& -\left(\frac{\left[\omega(\mathrm{T})_{\lambda}^{2}\right]_{\lambda \phi}}{2[\sigma]_{\lambda \sigma}}\right) \\
& \mathrm{BKZ}=\mathrm{c}_{1} \int_{\mathrm{p}_{1}}^{\mathrm{p}_{2}} \int_{\phi_{1}}^{\phi_{2}} \frac{1}{2 \mathrm{~g}}\left(\mathrm{u}\left[\mathrm{u}^{2}+\mathrm{v}^{2}-(\mathrm{u})_{\lambda}^{2}-(\mathrm{v})_{\lambda}^{2}\right]\right) \mathrm{d} \phi \mathrm{dp} \\
& +\mathrm{c}_{2} \int_{\mathrm{p}_{1}}^{\mathrm{p}_{2}} \frac{1}{2 \mathrm{~g}}\left(\left[\mathrm{v} \cos \phi\left[\mathrm{u}^{2}+\mathrm{v}^{2}-(\mathrm{u})_{\lambda}^{2}\right]\right]_{\lambda}\right) \mathrm{dp} \\
& -\left(\frac{1}{2 \mathrm{~g}}\left[\omega\left[\mathrm{u}^{2}+\mathrm{v}^{2}-(\mathrm{u})_{\lambda}^{2}-(\mathrm{v})_{\lambda}^{2}\right]\right]_{\lambda \phi}\right) \\
& \mathrm{BKE}=\mathrm{c}_{1} \int_{\mathrm{p}_{1}}^{\mathrm{p}_{2}} \int_{\phi_{1}}^{\phi_{2}} \frac{1}{2 \mathrm{~g}}\left(\mathrm{u}\left[(\mathrm{u})_{\lambda}^{2}+(\mathrm{v})_{\lambda}^{2}\right]\right) \mathrm{d} \phi \mathrm{dp} \\
& +\mathrm{c}_{2} \int_{\mathrm{p}_{1}}^{\mathrm{p}_{2}} \frac{1}{2 \mathrm{~g}}\left(\left[\mathrm{v} \cos \phi\left[(\mathrm{u})_{\lambda}^{2}+(\mathrm{v})_{\lambda}^{2}\right]\right]_{\lambda}\right) \mathrm{dp} \\
& -\left(\frac{1}{2 \mathrm{~g}}\left[\omega\left[(\mathrm{u})_{\lambda}^{2}+(\mathrm{v})_{\lambda}^{2}\right]\right]_{\lambda \phi}\right)
\end{aligned}
$$

where

$$
\begin{aligned}
& \mathrm{c}_{1}=-\left[\mathrm{r}\left(\lambda_{2}-\lambda_{1}\right)\left(\sin \phi_{2}-\sin \phi_{1}\right)\right]^{-1} \\
& \mathrm{c}_{2}=\left[\mathrm{r}\left(\sin \phi_{2}-\sin \phi_{1}\right)\right]^{-1}
\end{aligned}
$$

where $\mathrm{p}_{1}$ and $\mathrm{p}_{2}$ are, respectively, the maximum and minimum pressure, $\mathrm{T}$ is temperature, $\mathrm{g}$ is the magnitude of gravity's acceleration, $r$ is the average radius of Earth, $u$ and $v$ are the zonal and meridional components of wind vector, respectively and $\sigma$ is the static stability parameter given by:

$$
[\sigma]_{\lambda \phi}=\left[\frac{\mathrm{gT}}{\mathrm{c}_{\mathrm{p}}}-\frac{\mathrm{gp}}{\mathrm{R}} \frac{\partial \mathrm{T}}{\partial \mathrm{p}}\right]_{\lambda \phi}
$$

The authors of this work declare that there is no conflict of interests regarding the publication of our paper.

This is an Open Access article distributed under the terms of the Creative Commons Attribution
Non-Commercial License which permits unrestricted non-commercial use, distribution, and reproduction in any medium provided the original work is properly cited. 